\title{
Kent Ormanları Karbon Potansiyelinin Türkiye Gönüllü Karbon Kredi Piyasasına Entegre Edilmesinin Önemi
}

\author{
Hasan Volkan ORAL* \\ * İstanbul Aydın Üniversitesi, Mühendislik Fakültesi, İnşaat Mühendisliği Bölümü, Florya Halit Aydın Kampüsü, \\ 34295, İstanbul
}

\section{Öz}

Küresel ısınma ve iklim değişikliğinin en önemli nedenlerinden biri de kontrolsüz şekilde kullanılan fosil yakıt kullanımı ve sonucunda ortaya çıkan karbon türevli seraurl gazlarıdır. $\mathrm{Bu}$ gazlardan Karbondioksit $\left(\mathrm{CO}_{2}\right)$ salımını kontrol edebilmek için Sürdürülebilir Kalkınma prensipleri ile uyumlu Temiz Kalkınma Mekanizması (Clean Development Mechanism) geliştirilmiştir. Karbon piyasaları bu mekanizma içerisinde yer alan araçlardan biridir. Gönüllü Karbon Piyasaları bu mekanizma altında yeralmaktadır. Bu piyasa sistemi Türkiye'de mühendislik ve son yıllarda finans disiplinleri aracılığı ile irdelenmeye çalışılmaktadır. Bu konuda özellikle orman ekonomisi özelinde kent ormancılığının gönüllü karbon kredileri için değerlendirilebilme potansiyeli görmezden gelinmektedir. Yurtdışında özellikle son yıllarda yapılan bir çok yayında kent ormanlarının da sertifikalı veya gönüllü karbon piyasaları değerlendirme süreçlerine alındığını görebilmekteyiz. Bir projeye ait karbon kredilerini oluşturma, fiyatlandırma ve kredileri satin alacak alıcıların bulunması aşamasında, ilgili projelerin sosyo-ekonomik faktörler ve çevreye olan etkilerinin de değerlendirilmeye alındığı görülmektedir. Bu noktadan hareketle kent ormanlarının doğal ekosisteme ve sosyo-ekonomik parametreler üzerine olan yararları gözden kaçırılmamalıdır. Halen Türkiye'de istenen düzeyde gelişme gösteremeyen gönüllü karbon karbon piyasası uygulaması, kent ormancılığının da sisteme dahil edilmesi ile olumlu yönde gelişme gösterebilir, ekonomik değeri artabilir. Bu çalışmada, Türkiye'deki kent ormanlarının gönüllü karbon piyasasına entegre edilebileceği bir sistem önerisinde bulunulmuştur.

Anahtar Kelimeler: İklim değişikliği; karbon kredileri; orman ekonomisi, kent ormancılığ1; COP21, sürdürülebilir kalkınma.

\section{The Importance of Integrating the Urban Forest Carbon Potential to the Turkey Voluntary Carbon Credit Market}

\begin{abstract}
One of the most important causes of global warming and climate change is the uncontrolled use of fossil fuels and the resulting carbon-derived greenhouse gases. In order to control the emission of carbon dioxide $\left(\mathrm{CO}_{2}\right)$ from these gases, a Clean Development Mechanism has been designed in line with the principles of Sustainable Development. Carbon markets are one of the instruments within this mechanism and Voluntary Carbon Markets also fall under this mechanism. This system is aimed to examine the market through engineering and financial discipline in recent years in Turkey. In this regard, the potential of the forest economics, especially urban forestry, to be evaluated for voluntary carbon credits is ignored. In many scientific publications abroad, we can see that the carbon potential of the urban forests are included in the evaluation processes of certified or voluntary carbon markets. It is seen that the socio-economic factors and the environmental impacts of the related projects are taken into consideration in the process of creating carbon pricing, and finding buyers to purchase the credits. From this point of view, the benefits of urban forests to the natural ecosystem and socio-economic parameters should not be overlooked. The voluntary carbon market of Turkey is not in the desired position, which creates benefit for the domestic economy. By inserting and integrating the urban forest potential carbon potential to the voluntary carbon of market, perhaps the quality and the economic value of the voluntary carbon market might be increased. In this study an integrated system is proposed, which covers the input of urban carbon potential in Turkey.
\end{abstract}

Keywords: Climate change; carbon credits; urban forestry; forest economy; COP21, sustainable development. 


\section{Giriş}

Küresel ısınmanın doğada yarattı̆gı olumsuz etkileri azaltmak için 2000'li yılların başlarında bazı teknolojik ve finansal uygulamalar hızla hayata geçirilmiştir. Sürdürülebilir kalkınma politikaları ve uygulamalarının da çevresel, sosyal ve ekonomik olarak Dünya'da uygulanması ile birlikte karbon piyasaları ve bu piyasaların en önemli alt bileşenlerinden olan karbon vergileri literatürde en fazla bilinen finansman araçları olarak yer almıştır. Gerek karbon piyasası, gerekse karbon vergisi kavramları aslında Türkiye için halen çok yeni olan kavramlardır. Türkiye, Gönüllü Karbon Piyasaları (Verified Emission Reduction- VER) çerçevesinde aktif olarak on yıldan az bir süre içerisinde yer almaktadır. Karbon vergisi konusu halen Türkiye için yabancı ve tartışılmaya devam eden bir kavramdır. Türkiye'de nitelikli ve Avrupa Birliği Karbon Piyasası benzeri bir karbon piyasası kurma çalışmaları "Karbon Piyasasına Hazırlık Ortaklığı Projesi- PMR” adı altında Dünya Bankası finansörlüğünde, Çevre ve Şehircilik Bakanlığı koordinatörlüğünde halen devam etmektedir. Bu proje eğer başarılı bir şekilde sonlandırılırsa hem Karbon Piyasası ülkede tam olarak kurulacak, hem de Ulusal İklim Değişikliği Fonu gibi oluşumların önü açılabilecektir. Bu konunun bir diğer aktörü de ormancılık sektörüdür. Her ne kadar karbon vergisi, karbon kredisi gibi kavramlar finans literatüründe yer alsa da ormanların potansiyel karbon yatakları olması (Goodale ve ark.,2002; Pan ve ark.,2011) ve ormanlardaki toprak örtüsü içerisindeki azımsanmayacak miktardaki organik madde (Evrendilek ve ark., 2004) miktarından dolayı karbon döngüsünde (Brown ve Lugo, 1982; Nepstad ve ark.,1994) yer almaları açısından bu konuya dahil edilmesi gerekmektedir. Buna ek olarak, son yıllarda ormansızlaştırma sonucu atmosfere salınan karbondioksit (CO2) miktarının küresel ısınmada etkin bir rol oynadığı Türkiye'de de yapılan modelleme ve saha çalışmalarına dayanan yayınlarla (Oral ve ark., 2013; Küçüker ve ark., 2015) ortaya konmuştur.

Geleneksel ormancılık anlayışı yanında ortaya atılan kent ormanları kavramları, yine karbon kredilerinin gelişmesi ve uygulanması (Poudyal ve ark.,2011) Öner ve ark.,(2007)'nın da ifade ettiği gibi son yıllarda önem kazanmış, doğal orman vejetasyon formasyonuna verimli topraklar üzerinde , yerleșim yerlerinin içinde veya çevresinde kalmış veya korunmuş, veyahut ağaçlandırılarak yeniden kentlinin doğrudan ya da dolaylı olarak yararlanabildiği, veya bir şekilde faydalanabileceği uzaklıkta, mevcut ekosistemin devamlılığını sağlayabileceği genişlikte ve formadaki orman alanları kent ormanı olarak tanımlanmaktadır.

Yapılan literatür taramasında kent ormancılı̆̆ı konusunda bazı araştırmacıların (Görcelioğlu, 1999; Serin ve Gül, 2006; Y1lmaz ve ark., 2006; Öner ve ark., 2007; Gül ve Küçük, 2009; Kiper ve Öztürk, 2011; Durkaya ve ark.,2016) çalışmalarına rastlanmıştır ancak bu ormancılık türünün karbon kredileri için değerlendirme yöntemlerine yönelik bir yoruma rastlanılamamıștır. Bu çalıșmalara ek olarak Başsülü (2014), yapmış olduğu doktora çalışmasında genel olarak ormancılık sektöründe karbon kredileri konusunu istatistiksel yaklaşımlarla ele almıştır ancak Türkiye'nin de içerisinde yer aldığı gönüllü karbon piyasalarına nasıl entegre olabileceği konusu irdelenmemiştir. Ülgen ve Güneş (2016)'de “Ağaçlandırma Karbonu” adlı çalışmalarında orman varlıklarının karbon sertifikasyon projelerinde kullanılan ve standartlaştırılmış yöntemleriyle birlikte yer almaları gerektiğini açıklamışlardır. Ülgen ve Güneş (2016)'ın yaptıkları çalışmada üzerinde durdukları nokta ağaçlandırmaya dayalı orman karbon kredisi üretme hakkında mevzuat hükümleri ve yasal boşlukların bir an önce giderilmesi gerektiğinin öneminidir ve 2016'dan günümüze bu alanda herhangi bir somut gelişme gözlenenemiştir. Diğer yandan Ülgen ve Güneş (2016)'in çalışmasında da Türkiye'de var olan gönüllü karbon ekonomisine nasıl bir entegrasyon yapılabileceği belirtilmemiştir. Buna ek olarak, Yetiş ve Özden (2019)'de “Türkiye'de Karbon Piyasalarının Gelişimi ve Ormancılığa Etkisi” adlı çalışmalarında konuyu geniş açıdan ele alarak, Türkiye'de sera gazı ile mücadelede iklim değişim politikalarının henüz tam anlamıyla belirlenmemiş olduğunun altını çizmişlerdir. Bu çalışmanın amacı, kent ormanlarının doğal ekosisteme, sosyo-ekonomik parametreler üzerine olan yararlarının yeniden hatırlatılması ile birlikte, küresel ısınma ile mücadelede önemli bir yer tutan karbon kredilerinin Turkiye'de uygulanan “Gönüllü Karbon Piyasasına nasıl entegre edilebilir?” sorusunun cevabını vermeye çalışmaktır. Çalışmanın varmak istediği bir diğer amaç da literatürde bu alandaki boşluğu doldurmakdır.

\section{Karbon Kredilerinin Alım ve Satımı}

Bu alım ve satımlar temel olarak sera gazı salınımlarında gerçekleştirilen azaltımlar karşılığında edinilen karbon sertifikalarının ticaretinin yapılabildiği bir piyasa içerisinde gerçekleşmektedir. Borsa mantığı ile işleyen karbon piyasasında sertifikalar, diğer bir deyişle krediler, alınıp satılmakta, firmalar hem azaltım hedeflerine ulaşmaya çalışmakta hem de kâr elde etmektedir (Can, 2018). Bu piyasa, bir açıdan devletlerin iklim değişikliği üzerine kurgulanan çeşitli hedef ve politikalarından bağımsız bir şekilde geliştirilmiş, gerek iş dünyasından gerekse de sivil toplum kuruluşları ve yerel yönetimlerden en küçük yapı olan bireylere kadar konu ile ilgili her kesimin karbon denkleştirme amacıyla katılım sağlayabileceği bir piyasa çeşididir. İklim değişikliği sebebiyle gerek makro düzeyde gerekse de bireyler üzerinde bilincin giderek artması ve karbon denkleştirmenin güvenilir bir önlem stratejisi olduğu gerçeğinin kabul edilmesi bu piyasaların son yıllarda artan hızla geliştirmiştir (eie.gov.tr,2016). Bu piyasa sera gazlarının azaltılması amacıyla gerekli finansal kaynağın yaratılmasını 
hedeflemekte ve temelleri Katılımc1lar Konferans1 (Conference of Parties - COP) COP7 Kyoto toplantıs1 ile atılmıştır. Kyoto toplantısına katılan ve protokole imza atan her üye ülkeye belirlenmiş bir karbon emisyon kotası verilmiştir. Protokolü imzalayan ülkelerin bu kotaları kendi üreticileri arasından paylaşması temel esastır. Piyasanın çalışma prensibine göre eğer herhangi bir üretici şirket ya da ülke kendi ait belirlenmiş kotasını aşarsa daha az karbon emisyonu üreten ülke ya da üretici şirket tarafından karbon kotası satın alabilecektir (Demir,2007). Bu piyasa sistemi içerisinde alım-satım işlemine karbon ticareti, bu ticaret esnasında da satın alınan veya satılan mal a da karbon kredisi ismi verilmektedir. Piyasa içerisinde tanımlanmış karbon kredileri Karbon Denge Kredisi (COCs) ve Karbon Azaltım Kredisi (CRCs)'dir.

Bu piyasa Zorunlu ve Gönüllü Piyasa Sistemleri olarak iki grup altında toparlanabilir. Zorunlu Piyasa Sistemi, Emisyon Ticareti (ET - Emission Trade) (Protokol: Madde 17), Temiz Kalkınma Mekanizması (TKM - Clean Development Mechanism) (Protokol: Madde 12) ve Ortak Yürütme (OY - Joint Implementation) (Protokol: Madde 6) alt uygulamalarından meydana gelmektedir. Emisyon Salım ticareti bütünüyle piyasa tabanlı bir araç iken, JI ve CDM karbon piyasasını besleyen proje tabanlı iki mekanizmadır (iklim.csb.gov.tr, 2019; climatevolunteers.com, 2019).

Gönüllü karbon piyasası bireylerin, kurum ve kuruluşların, sivil toplum örgütlerinin faaliyetleri sonucu oluşan seragazı salımlarını gönüllü olarak azaltmalarını ve denkleştirmelerini kolaylaştırmak amacıyla oluşturulmuş bir pazardır. Bu piyasalardaki süreç, Kyoto Protokolü kapsamında zorunlu olarak uygulanan Esneklik Mekanizmalarına benzer bir sürece sahiptir. Gönüllü karbon piyasasını Kyoto Protokolü kapsamındaki zorunlu süreçlerden ayıran en önemli farkların başında ise, işlem gören salım azaltımlarının ulusal yükümlülük kapsamı dışında kısacası, devletlerin belirlediği politikalar ve hedeflerden bağımsız olarak gönüllülük esasında gerçekleştirilmeleridir. Katılım için herhangi bir sınırlama yoktur (climatevolunteers.com, 2019).

\section{Karbon Kredisi Nedir?}

2005 yılında 181 dünya ülkesinin onaylaması ile yürürlüğe giren Kyoto Protokolü, 40 gelişmiş ülkenin sera gazı salınımlarını belirli limitler dahilinde sınırlanması ile bir açıdan bu tür gazlara ticari bir değer kazandıran bir anlaşmadır. Protokol tarafından belirlenen ulusal kotaların aşılması istemeyen belirli ülkelerin yanı sıra Avrupa Birliği Salınım Ticareti Tasarısına tabi olan çeşitli endüstriyel kuruluşlar ve sahip oldukları çevresel duyarlılıklarını göstermek isteyen çeșitli firmalar da dünya üzerindeki sera gazı azaltımını sağlayan projeleri belgeleyen kredi sertifikasyonlarını satın alarak bir açıdan projelerin destekçisi olmuşlardır. Kyoto Protokolüne taraf olmayan çeşitli ülkelerde (Türkiye'de bu ülkeler grubu içinde yer almakta) sera gazı salınımının azaltımını sağlayan projeler gönüllü olarak gerçekleştirilen salınım azaltımı olarak değerlendirilmekte ve buna göre kredi sertifikasyonları gerçekleștirilmektedir. Kredi sertifikasyonları verilirken, projelerin sağlamış olduğu sera gazı azaltımı için 1 ton $\mathrm{CO}_{2}$ 'in baz birim olarak kabul edildiği bu sistemde farklı türde sera gazları birbirleri cinsinden hesaplanıyor olsa da çoğunlukla karbon kredisi olarak adlandırıldığı görülmektedir. Kredi sertifikasyonlarının alınabilmesi için gerçekleştirilen emisyon azaltımına yönelik karmaşık olarak değerlendirilebilecek başvuru, kayıt, onay, planlama ve takip süreçlerinin başarıyla tamamlanmasını gerektirir. Dünya ölçeğinde bakıldığında bu krediler ticari olarak alınıp satılabilmekte ve cok hızlı bir şekilde büyüyen bir pazar yaratmaktadır (eğitimler.info, 2018).

\section{Karbon Piyasa Uygulamaları ve Türkiye}

Türkiye'de şu anda 2005 'ten bu yana karbon emisyonu azaltılması için gönüllülük esasına dayanan "Gönüllü Karbon Piyasaları" uygulamaları devam etmektedir. Bu piyasada ticareti yapılan emisyon sertifikalarına Gönüllü Emisyon Azaltım (Voluntary Emission Reduction- VER) sertifikası adı verilmektedir. İşletmeler faaliyetleri sebebiyle oluşturdukları sera gazı emisyonlarını dengelemek isteyen firmalar, emisyon miktarlarının hesaplanmasıyla bu emisyonlarını azaltmak ve dengelemek için emisyon azaltımı sağlayan projelerin üretmiş oldukları karbon sertifikalarını sosyal sorumluluk prensibi çerçevesinde satın almaktadırlar (eie.gov.tr, 2016).

25 Nisan 2012 tarih ve 28274 sayılı Resmi Gazete'de yayımlanarak Gönüllü Karbon Piyasaları'nın çalışmaları "Sera Gazi Emisyon Azaltımı Sağlayan Projelere İlişkin Sicil İşlemleri Tebliği” ile düzenlenmiştir. Bu tebliğe göre başta özel teşebbüsler olmak üzere ait sera gazı emisyon azaltımın projelerinin kayıt altına alması hedeflenmiştir (resmigazete.gov.tr, 2016). Yönetmeliğin temel amacı Kyoto Protokolü Ek.I listesinde bulunan (emisyonların önemli bir kısmını oluşturan çimento, seramik, kağıt ,elektrik ve buhar üretimi, , demir-çelik, kireç, ve cam üretimi gibi) çeşitli faaliyetlerden kaynaklanan sera gazı emisyonlarının sırasıyla izlenmesi, doğrulanması ve son olarak raporlanmasıdır (ab.immib.org.tr, 2016). 


\section{COP21 Paris Anlaşmasından sonra Dünya'da Uygulanılması Öngörülen Karbon Piyasası Sisteminin Özellikleri}

2015'te Paris'te gerçekleşen COP21 Paris toplantısı ile Kyoto Toplantısında kabul edilen Karbon Piyasaları mekanizmalarının tamamıla değiştirilmesi ve yeniden bir yapılandırılmaya gidilmesi kabul edilmiştir. Öncelikle COP21'e katılan ülkelerin tamamı yayımladıkları Ulusal Niyet Katkı Beyanı (INDC) ile karbon salınımlarını 2020 ile 2030 yılları arasında indireceklerini taahhüt etmişlerdir.

COP21'de kabul edilen 6. Madde'ye göre protokolü imzalayan bütün ülkeler Ulusal Niyet Katkı Beyanlarında belirtilen oranlara emisyonlarını indirmek için Kyoto Toplantısı'nda kabul edilen Karbon Piyasası Mekanizmalarını uygulama zorunluluğu altında olmayacaklardır. Bunun yerine gönüllülük esasına dayanılarak "internationally transferred mitigation outcomes" yani "Uluslararası Transfer Edilebilir Azaltım Sonuçları" olarak adlandırılan yeni bir karbon piyasası önerilmiştir. Aslında bu sistemin çalışma mekanizması Kyoto'da kabul edilen Zorunlu Karbon Piyasa Mekanizmaları elemanlarından TKM ve OY sistemlerinin birleşiminden oluşmaktadır. Bu piyasa mekanizmasının 2020'den sonra devreye alınması öngörülmektedir (Marcu,2016).

\section{Kent Ormanlarının Çevre Parametrelerine Olan Etkileri}

Bu başlık altında başlıca çevresel parametreler içerisinde yer alan hava kalitesi, toprak ekosistemi, su kaynakları, katı atık yönetimi, biyolojik çeşitlilik ve peyzaj üzerine kent ormanlarının etkileri anlatılmıştır.

\subsection{Hava kalitesi}

$\mathrm{CO}_{2}$ emisyonlarının önemli bir oranda tutulması ve bitkilerin kirletici maddeleri atmosfer ortamından belirlenen 3 şekilde yardımcı olma prensibiyle: yapraklar veya toprak yüzeyi tarafindan emme; yaprak yüzeyinde aerosoller ve parçacıkların atılımı ve hava hareketlerinin yavaşlaması yüzünden vejetasyon kıyısında rüzgar yönünde partiküllerin taşınması aracılığı ile hava kalitesini artırması (Öner ve ark., 2007).

\subsection{Toprak ekosistemi}

Kent ormanları genel olarak hassas ortamlarda kurulmuş olan kentler çevresinde heyelan ve erozyon etkilerine karşı toprağı korumaktadırlar (Öner ve ark., 2007).

\subsection{Su kaynaklarının sürdürülebilir olarak kullanılması}

Kent ormanları su döngüsü içerisinde yerleşim merkezlerıne düşen yağmurun yeniden döngüye katılmasında aktif bir rol üstlenmektedir (Öner ve ark., 2007; Elis, 2011).

\subsection{Katı atık yönetimi}

Kent ormanları içerisinde katı atıkların, ayrıştırılarak toplanması ve tasnif edilmesi, katı atık yönetiminin en temel prensibini yerine getirerek bu konunun uygulanmasında en önemli aktörlerden biri olmaktadır (MesjazLech, 2014).

\subsection{Biyolojik çeşitlilik}

25 Agustos 2015 tarihli, 29459 sayılı Resmi Gazete’ye göre park-bahçe, mezarlık ve yol kenarı ağaçlandırmalarında zararlı organizmalar ile teknik mücadele belirli bir metod izlenerek yapılmaktadır (resmigazete.gov,2015). Yönetmelik gereği bu mücadelede kimyasal veya sentetik türevli preparatların kullanımı yasaklanmıştır. Sonuç olarak kent ormanlarında bitki ve hayvan çeşitlerinde artış saptanmıştır.

\subsection{Peyzaj (Estetik)}

Kentler çevresinde yer alan ormanlar estetik açıdan kentin bir açıdan katı ve keskin olan hatlı oluşumlarını yumuşatırlar ve kontrast şekil ve tekstürler oluşturarak bir açıdan hem etkileyici hem de oldukça ilginç görünüm yaratmaktadır. (Öner ve ark., 2007).

\section{Kent Ormanlarının Enerji Kullanımı ve Tasarrufuna Etkileri}

Yerleşim yerlerindeki konutların çevresindeki vejetasyonun genel olarak 1sınmak için \%5-15 ve soğutma için ise \%5-50 arasında olumlu etki yaptığı tespit edilmiştir (Öner ve ark., 2007; Yılmaz ve ark.,2006). Martini ve ark., 
(2017) yaptıkları çalışmada kent ormanlarında bulunan vejetasyon yoğunluğu ile mikroklima değişimleri arasında istatiksel olarak korelasyon bulduklarını bildirmişlerdir.

\section{Kent Ormanlarının Sosyo-Ekonomik Parametreler Üzerine Etkileri}

Sosyo-Ekonomik parametrelerden sosyal ilişkilerin gelişmesi, çevreyi koruma bilincive çevre vatandaşlığı kavramları bu başlık altında incelenmiştir.

\subsection{Sosyal Ilişkilerin Gelişmesi, Sosyalleşme}

Bogenç ve ark (2018) kent ormancılığı kavramını, kent-parkları şeklinde irdeleyerek bu alanlarda bireylerin sosyal ilişkilerini, doğa ile birlikte geliştirdiklerini belirtmiştir.

\section{2 Çevreyi Koruma Bilincinin Çocuklara Verilmesi Ve Çevre Vatandaşlığı Bilincinin Oluşması}

Kent ormanları çocukların; iletişim, işbirliği, yaratıcılık, denetim gibi yeteneklerinin gelişmesini sağlar. Bu olumlu etki, toplumun da yararınadır (Yılmaz ve ark.,2006). Bu sayede sürdürülebilirlik kavramı paralelinde çocuklarda çevre bilinci ve daha sonra bu bilincin çevre vatandaşlığına evrilmesinin temelleri atılabilmektedir (COST ENEC, 2018).

Tablo 1. Kent ormanlarının çevre ekosistemine olumlu etkileri (Yılmaz ve ark., 2006, Öner ve ark., 2007, Kiper ve Öztürk,2011; Martini ve ark., 2017, COST ENEC, 2018).

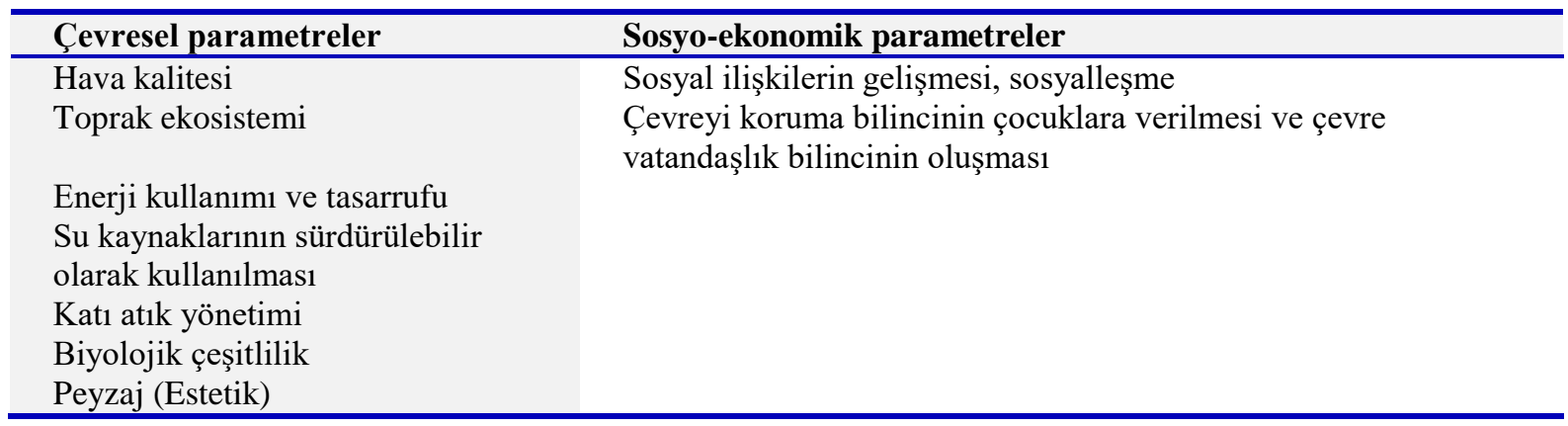

\section{Kent Ormanlarından Karbon Kredileri Nasıl Elde Edilebilir?}

Yapılan literatür çalışmasında kent ormanlarından karbon kredilerinin üretilmesi konusunda bölge ve ülkeler bazında takip edilen ve kabul edilen standart bir yöntem bulunamamıştır. Poudyal ve ark. (2011), Amerika Birleşik Devletleri (ABD)'nde yaptığı çalışmada, ülke genelindeki kent ormanlarının sahip oldukları potansiyel kardon kredilerin kullanılması ve oluşturulan kredilere alıcı bulabilmek amacıyla önce kriter belirlenmesi işlemini yapmışlardır. Hazırlanan bir anket çalışması ile Kasım 2007 ile Ocak 2008'de yerel yönetimler,belediyeler ve ormancılıkla uğraşan sektör temsilcilerine ulaşılarak aşağıdaki Tablo 2'de gösterilen kriterler listesi oluşturulmuştur.

Tablo 2. Kent Ormanları için Karbon Kredisi Oluşturma Kriterleri (Poudyal ve ark.2011'den çevrilerek).

\begin{tabular}{ll}
\hline Kriter & Tanım \\
\hline Katkı değer özelliği & $\begin{array}{l}\text { Ek olarak, projenin yarattı̆̆ı emisyon azaltımının, projenin yokluğunda olacak } \\
\text { olanlara eklenmesi gerekir. }\end{array}$ \\
$\begin{array}{l}\text { Temel (Baseline) } \\
\text { Senaryonun }\end{array}$ & $\begin{array}{l}\text { Temel senaryo, offset projesinin katkısının ölçülebileceği, gerçekçi bir şekilde } \\
\text { belirlenmiş proje öncesi emisyon seviyesini veya emisyon azaltma kapasitesini }\end{array}$ \\
$\begin{array}{l}\text { Oluşturulması } \\
\text { Gerçeklik }\end{array}$ & $\begin{array}{l}\text { ifade eder. } \\
\text { Karbon ofsetin atmosferden gelen gerçek ya da gerçek emisyon azalmasını }\end{array}$ \\
$\begin{array}{l}\text { Miktar ve izleme } \\
\text { (Quantification and }\end{array}$ & temsil etmesini gerektirir. \\
Monitoring) & bölgesel detayların açık bir ifadesiyle kendine ait benzersiz bir plan gerektirir. \\
\hline
\end{tabular}


Tablo 2. Devam ediyor.

\begin{tabular}{ll}
\hline Kriter & Tanım \\
\hline Verifikasyon & $\begin{array}{l}\text { Verifikasyon, talep edilen mahsup kredilerin üçüncü bir tarafça bağımsız } \\
\text { olarak doğrulanmasının yapılmasını gerektirir. }\end{array}$ \\
Mülkiyet & Mülkiyet, proje mülkiyetinin açık bir tanımını ve ofseti satma hakkını ifade \\
& eder. \\
Kaçak & Kaçak, bir dengeleme projesi sonucunda olası kaymalardan kaçınılmasını veya \\
& emisyondaki artmayı gerektirir \\
Kalıcılık & Kalı̈ılık, atmosferden emilen ofsetin veya kalıcı karbon depolamasının geri \\
& dönüşümsüzlüğünü gerektirir. \\
Bölgesellik & Bölgesellik, dengeleme projelerinin emisyon kaynakları bölgesi içinde yer \\
& almasını gerektirir. \\
Ek-yararlar & Ek-yararlar, ofset projesinin yerel topluma yardımcı faydalarını ifade eder. \\
\hline
\end{tabular}

Moore (2008) tarafından ABD’nin Kolorado Eyaleti için yapmış olduğu kent ormanlarının karbon kredilendirme yöntemi çalışması, Amerika Birleşik Devletleri Tarım Bakanlığı (United States of America Department of Agriculture- USDA) tarafindan da esas kriter kabul edilerek, bu çalışmada ortaya atılan metodolojinin kent ormanlarına uygulanabileceğini belirtmiştir. Moore (2008)'a göre, kent ormanlarından karbon verileri elde edebilmek için, ağaçların dikim yılı,türü ve ölçüleri, ağaçlarda görülen hastalık türlerinden kent ormanlarından son kullanıcılara satılacak karbon verileri elde edilebilir.Bu konuda yapılmış başka bir çalışmada ise Walsh (2012), Nova Scotia'daki Dartmouth'da yer alan kent ormanları için sırasıyla çalışmanın aşamaları aşağıdaki şekilde belirtilmiştir.

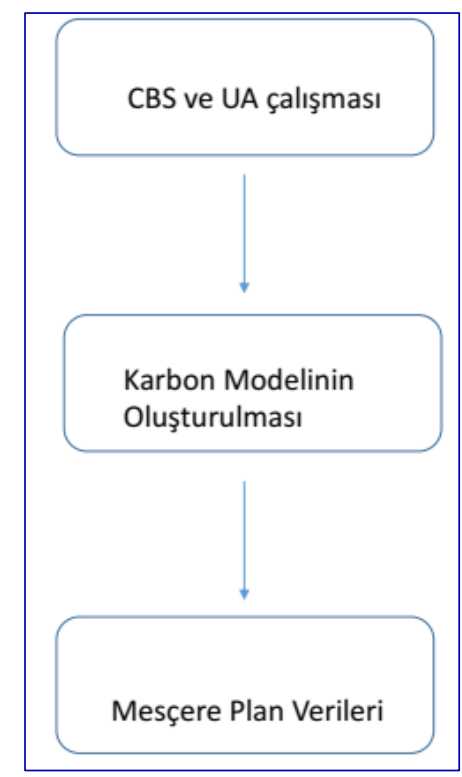

Şekil 1: Dartmouth Kent Ormanı Kabon Kredi Potansiyeli Belirleme Yöntemi (Walsh, 2012).

Coğrafi Bilgi Sistemleri (CBS) ve Uzaktan Algılama (UA) teknolojileri ile çalışma alanine ait arazi kullanımı, örtü dokusu verilerini toparlayarak bir model oluşturmuş ve oluşturulan bu modele mesçere verilerini de eklenerek, Dartmouth Kent Ormanlarının potansiyel karbon kredi miktarını hesaplanmıştır. Walsh (2012) yapmış olduğu bu çalışmasında, Poudyal ve ark. (2011)'de ortaya attığı kriterleri de kullanmıştır.

\section{Tartışma ve Sonuç}

Walsh (2012)'nin çalışmasında kullanılan yöntem, kent ormanları dışında Türkiye Ormanları'nda daha detaylı bir şekilde kullanılmaktadır. Örneğin, Değermenci ve Zengin (2016), Ormanlardaki karbon birikiminin konumsal ve zamansal değişiminin incelenmesi konusunda CBS tabanlı yaptıkları çalışmada Daday planlama birimi 
örneğini incelemişler ve çalışmalarında, ormanların sahip oldukları karbon stok değişimlerinin belirlenmesinde Uluslararası İklim Değişikliği Paneli (Intergovernmental Panel on Climate Change- IPCC) kılavuzunda yer alan ardışı iki envanter dönemi arasındaki karbon stok değişiminde meydana gelen farka dayanan yöntemi kullanmışlardır. Ancak,yapılan bu çalı̧̧manın sonuçları, karbon kredilerinin değerlendirilmesi için bir başka araştırıcı tarafından Türkiye şartları için kullanılmamış ve kent ormanlarının bu bağlamda nasıl değerlendirilebileceği sorusunun cevabı halen verilememiştir. Yolasığmaz ve ark. (2016)'da CBS kullanmadan her iki karbon birikim hesaplama yöntemini kullanarak Artvin Orman Şefliği'nde bir çalışma yapmış ve karbon birikimlerini tahmin etmişlerdir. Bu çalışmada da elde edilen sonuçların kent ormanları genelinde nasıl değerlendirilebileceği irdelenmemiş̧ir. Başsülü (2014), istatistik paket programları kullanarak, gerekli regresyon denklemleri yardımıyla Walsh (2012)'in yapmış olduğu çalıșmasında ortaya attığı hipoteze benzer bir hipotezi irdelemeye çalışmıştır. Ülgen H. ve Güneş (2016) de yaptıkları çalışmada yenilenebilir enerji kaynaklarından karbon kredileri elde edilmesinde takip edilen, proje dosyası açılması, sicil kaydı, doğrulama, takip etme gibi aşamaları ormancılık sektörü için belirtmişlerdir ancak bu ortaya atılan yöntemlerin Türkiye koşullarına göre uyarlanması ve yine Poudyal ve ark. (2011)'nın yaptığı şekilde bir kriter sisteminin önerilmesi gereklidir. Bu noktada en önemli görev ormancılık sektörü ile ilgilenen bütün paydaşlara düşmektedir. Öncelikli olarak bu paydaşların bir araya geleceği bir çalıştayın düzenlenmesi ilgili Bakanlıklar tarafından organize edilebilir ve çalıştay katılımcıları bu çalı̧̧manın Giriş Bölümü’nde bahsedilen “Karbon Piyasasına Hazırlık Ortaklığı Projesine" dâhil edilebilir. Aşağıdaki Şekil 2'de uygulanabilecek çalışma şekli önerisi gösterilmiştir.

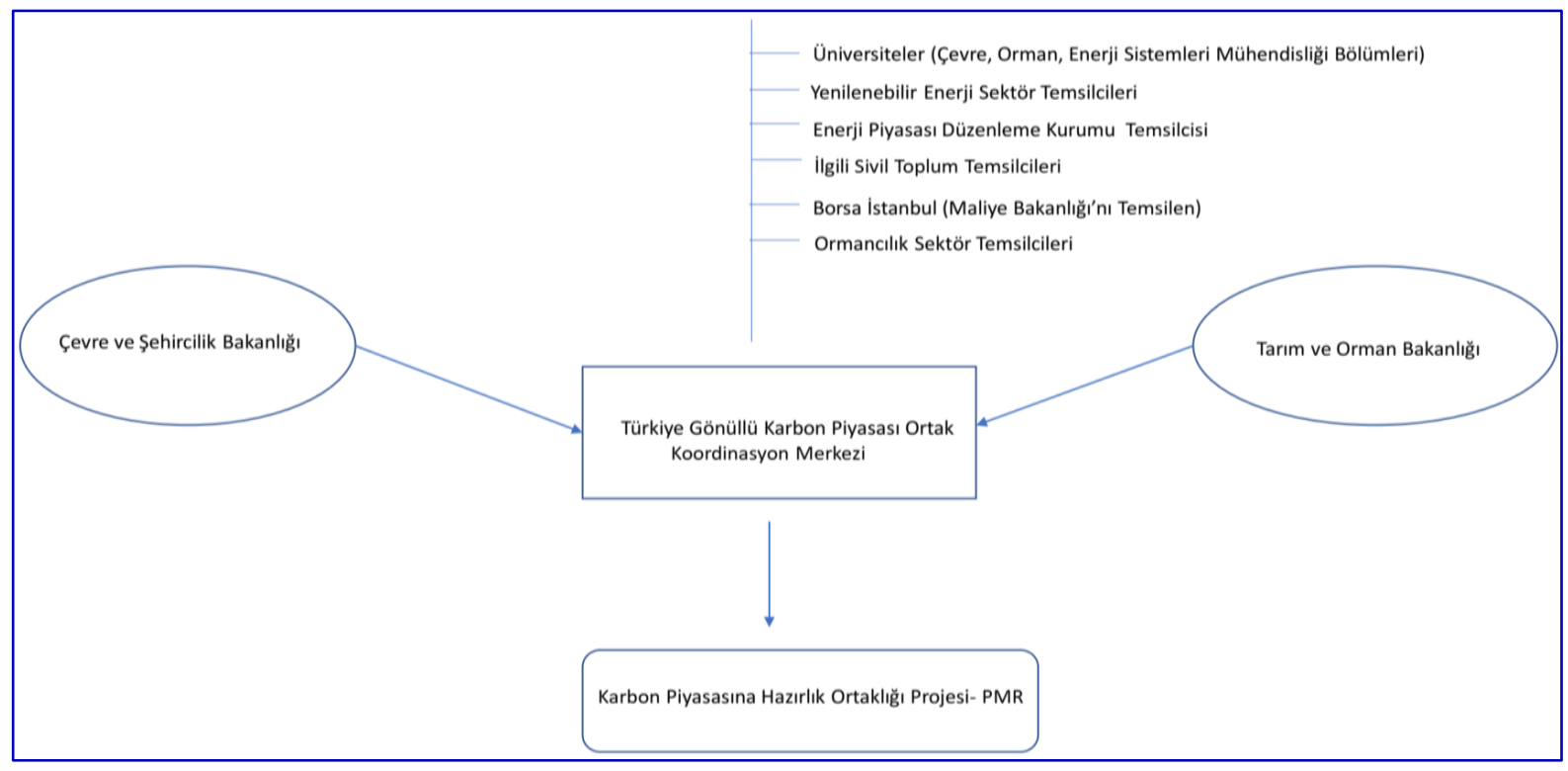

Şekil 2: Kent ormancıllğını da içerisine alan her iki Bakanlık eş güdümünde oluşturulacak Türkiye Gönüllü Karbon Piyasası Ortak Çalışma Modeli.

Türkiye'de Karbon Piyasası'nın takibinde bir piyasa oluşturabilme çalışmalarında etkin rol oynayan Çevre ve Şehircilik Bakanlığı verilerine göre Türkiye'de bu piyasanın işlemesi tam anlamıyla istenen noktada değildir ve iklim değişikliğine mücadele uygulanacak politikalar tam anlamıyla belirlenememiștir. Bakanlık tarafindan 2013 yılında Resmi Gazete'de yayımlanan "Gönüllü Karbon Piyasasi Proje Kayit Tebliği” nin uygulanmasında halen sıkıntıların yaşanması olasıdır. Bu konudaki en önemli kısıtlama, Tarım ve Orman Bakanlığı ile Çevre ve Şehircilik Bakanlığı'nın birlikte hareket edememesinden doğmaktadır. Bu iki Bakanlık 2011 öncesi aynı teşkilatlanma yapısında çalışırken (Çevre ve Orman Bakanlığı- ÇOB) Ormancılık sektörünü karbon piyasaları bakış açısından ele alınan bir rapor yayımlanarak (ÇOB,2010), sürecin Türkiye'de uygulama aşamaları, oluşturabilecek kriter aşamaları, dünyada kullanılan standartlar konusu detaylı bir şekilde ele alınmış ancak üzerinden geçen 10 sene gibi bir süre içerisinde somut bir adım atılamamıştır. Bu sürecin yeniden canlandırılması için öncelikle her iki Bakanlık da, bu konu hakkında aynı terminoloji üzerinden birbirleri ile iletişim kurarak bir komisyon oluşturabilir ve bu komisyon altında Türkiye'de uygulanmaya çalışılan karbon kredileri mekanizmasını yeniden planlanabilir. Ancak bu aşamalardan önce kent ormancıllğına yönelik yayımlanmış bütün literatürün yeniden gözden geçilerek bir arşiv sistemi oluşturulması hedeflenmelidir. Daha sonra Poudyal ve ark. (2011)'nın yaptığı gibi ve ÇOB (2010) Raporu'nda ortaya atılan kriter sistemi, COP21 Paris Anlaşması kriterleri de göz önüne alınarak güncellenmeli ve Türkiye için yeni bir kriter sistemi belirlenmelidir. Elde edilen sonuç ve değerlendirmeler sonrası bu çalışmada ortaya atılan entegrasyon önerilerinin uygulanması Karbon Kredisi değerlendirmelerinde Türkiye için yeni bir bakış açısı getirecektir. 


\section{Kaynaklar}

1. Başsüllü, Ç. (2014). Ormancılıkta Karbon Ekonomisi ve Borsası. SÜ Fen Bilimleri Enstitüsü, Orman Ekonomisi Anabilim Dalı, Isparta.

2. Bogenç, Ç. (2018).Kent Parklarında Sosyalleşme Mekânlarında ki Görsel Kalite Değerlendirmesi Rize Sahil Park1 Örneği", European Conference on Science, Art Culture, Antalya, TÜRKIYE, , pp.381-386

3. Brown, S., Lugo, A. (1982). The Storage and Production of Organic Matter in Tropical Forests and Their Role in the Global Carbon Cycle. Biotropica, 14(3), 161-187. doi:10.2307/2388024.

4. Can F (2018) Türkiye'de Uygulanan ve Gönüllü Karbon Piyasalarında Faaliyette Bulunan Projelerin Paydaş Katılımı Açısından Değerlendirilmesi, Ekonomi, Politika \& Finans Araştırmaları Dergisi,3(1): 117.

5. COST European Network for Environmental Citizenship (ENEC) (2018), http://cost.eu. Erişim Tarihi: 19.07.2019

6. Çevre ve Şehircilik $\quad$ Bakanlığı $\quad$ (2012). http://iklim.cob.gov.tr/iklim/AnaSayfa/birimler/mghg/flexiblemechanism.aspx?sflang=tr. Erişim Tarihi 01.08.2019.

7. Çevre ve Orman Bakanlığı (ÇOB) (2010). http://www.karbonkayit.cob.gov.tr/Karbon/Files/orman.pdf. Erişim Tarihi 01.08.2019.

8. Durkaya, B., Bekci, B., Varol, T. (2016). Bartın Kent Ormanının Karbon Tutma, Oksijen Üretimi ve Rekreasyonel Açıdan Değerlendirilmesi. Kastamonu Uni., Orman Fakültesi Dergisi, 16(1), 111-119.

9. Elektrik İşleri Etüit İdaresi (2016). eie.gov.tr. Erişim Tarihi 01.08.2019.

10. Ellis JB (2013). Sustainable surface water management and green infrastructure in UK urban catchment planning, Journal of Environmental Planning and Management, 56:1, 2441, DOI: 10.1080/09640568.2011.648752.

11. Evrendilek, F., Celik, I., Kilic, S. (2004). Changes in soil organic carbon and other physical soil properties along adjacent Mediterranean forest, grassland, and cropland ecosystems in Turkey. Journal of arid environments, 59(4), 743-752.https://doi.org/10.1016/j.jaridenv.2004.03.002.

12. Goodale, C. L., Apps, M. J., Birdsey, R. A., Field, C. B., Heath, L. S., Houghton, R. A., ... \& Nabuurs, G. J. (2002). Forest carbon sinks in the Northern Hemisphere. Ecological applications, 12(3), 891-899.

13. Görcelioğlu, E. (1999). Kent ormanları ve İklim Değişmesi, İstanbul Üniversitesi Orman Fakültesi Dergisi, B, (49), 1-4.

14. Gül, A., Küçük, V. (2009). Kentsel Açık-Yeşil Alanlar ve Isparta Kenti Örneğinde İrdelenmesi. Turkish Journal of Forestry, 2 (1), 27-48.

15. Kiper, T., Öztürk, A. G. (2011). Kent ormanlarının rekreasyonel kullanımı ve yerel halkın farkındalığı: Edirne Kent (İzzet Arseven) Ormanı örneği. Tekirdağ Ziraat Fakültesi Dergisi, 2011 8(2).

16. Kucuker, M. A., Guney, M., Oral, H. V., Copty, N. K., Onay, T. T. (2015). Impact of deforestation on soil carbon stock and its spatial distribution in the Western Black Sea Region of Turkey. Journal of environmental management, 147, 227-235.

17. Marcu, A. (2016). Carbon Market Provisions in the Paris Agreement (Article 6), https://www.ceps.eu. Erişim Tarihi 15.07.2019.

18. Martini, A., Biondi, D., Batista, A. C. (2017). Urban Forest Components Influencıng Microclimate and Cooling Potentral. Revista Árvore,41(6), e410603. Epub November 30, 2017.https://dx.doi.org/10.1590/1806-90882017000600003.

19. Mesjaz-Lech, A. (2014). Municipal Waste Management in Context of Sustainable Urban Development. Procedia, 151 (30),244-256.

20. Moore, R. (2008). Urban Forestry Carbon Credits in Colorado, https://www.fs.usda.gov/Internet/FSE_DOCUMENTS/stelprdb5201664.pdf. Erişim Tarihi 06.08.2019

21. Nepstad, D. C., de Carvalho, C. R., Davidson, E. A., Jipp, P. H., Lefebvre, P. A., Negreiros, G. H., ... , Vieira, S. (1994). The role of deep roots in the hydrological and carbon cycles of Amazonian forests and pastures. Nature, 372(6507), 666-669. http://dx.doi.org/10.1038/372666a0.

22. Oral, H., Guney, M., Kucuker, M. A., Onay, T. T., Copty, N. K., Mater, B., Yenigun, O. (2013). The impact of hazelnuts in land-use changes on soil carbon and in situ soil respiration dynamics. Journal of environmental management, 129, 341-349.

23. Öner, N., Ayan, S., Sivacıŏlu, A., İmal, B. (2007). Kent ormancılığı ve kent ormanlarının çevresel etkileri. Kastamonu Üniversitesi Orman Fakültesi Dergisi, 7(2), 190-203.

24. Pan, Y., Birdsey, R. A., Fang, J., Houghton, R., Kauppi, P. E., Kurz, W. A., ... , Ciais, P. (2011). A large and persistent carbon sink in the world's forests. Science, 333(6045), 988-993.

25. Poudyal, N. C., Siry, J. P., Bowker, J. M. (2011). Quality of urban forest carbon credits. Urban Forestry \& Urban Greening, 10(3), 223-230. 
26. Serin, N., Gül, A. (2006). Kent Ormancılığı Kavramı ve Isparta Kent İçi Ölçeğinde İrdelenmesi, Üniversitesi Orman Fakültesi Dergisi, Seri: A, Sayı: 2, Sayfa: 97-115.

27. Ülgen, H., Güneş, Y. (2016). Ağaçlandırma Karbonu. Doğa Koruma Merkezi, Ankara.

28. Walsh, J. A. (2012). Potential Urban Forest Carbon Sequestration and Storage Capacities in Burnside Industrial Park, Nova Scotia.Dalhousie Universitesi. Yüksek Lisans Tezi.

29. Yetiş, Ş., Özden, S. (2019). Türkiye'de Karbon Piyasasının Gelişimi ve İklim Değişikliği Üzerine Olan Etkisi. Sosyal Bilimler Dergisi,6 (34),457-477.

30. Resmi Gazete (2016). http://www.resmigazete.gov.tr/eskiler/2010/08/20100807-12.htm. Erişim Tarihi. 19.09.2019.

31. Yolasığmaz, H., Çavdar, B., Demirci, U., Aydın, İ. (2016). İki farklı yönteme göre karbon birikiminin tahmin edilmesi: Artvin Orman İşletme Şefliği örneği. Türkiye Ormancılık Dergisi, 17(1), 43-51.

32. İklim Gönüllüleri (2019). http://climatevolunteers.com/. Erişim Tarihi. 05.08.2019.

33. Resmi Gazete (2015). http://www.resmigazete.gov.tr/eskiler/2015/08/20150828M3.pdf . Erişim Tarihi. 19.07.2019.

34. Egitimler info (2018). https://www.egitimler.info/terimler-sozlugu/ekoloji-cevre-terimlerisozlugu/ekoloji-cevre-terimi-olarak-karbon-kredisi-nedir. Erişim Tarihi: 10.08.2019.

35. İstanbul Maden ve Metaller İhracatçı Birlikleri (2016) http://ab.immib.org.tr/. Erişim Tarihi: 15.09.2019. 